\title{
Fractional Differential Equations with Fractional Impulsive and Nonseparated Boundary Conditions
}

\author{
$\mathrm{Xi} \mathrm{Fu}{ }^{1}$ and Xiaoyou Liu ${ }^{2}$ \\ ${ }^{1}$ Department of Mathematics, Shaoxing University, Shaoxing, Zhejiang 312000, China \\ ${ }^{2}$ School of Mathematics and Physics, University of South China, Hengyang, Hunan 421001, China \\ Correspondence should be addressed to Xiaoyou Liu; liuxiaoyou2002@hotmail.com
}

Received 5 May 2014; Revised 30 June 2014; Accepted 30 June 2014; Published 16 July 2014

Academic Editor: Ali H. Bhrawy

Copyright (c) $2014 \mathrm{X}$. Fu and X. Liu. This is an open access article distributed under the Creative Commons Attribution License, which permits unrestricted use, distribution, and reproduction in any medium, provided the original work is properly cited.

\begin{abstract}
This paper studies the existence results for nonseparated boundary value problems of fractional differential equations with fractional impulsive conditions. By means of Schaefer fixed point theorem, Banach fixed point theorem, and nonlinear alternative of LeraySchauder type, some existence results are obtained. Examples are given to illustrate the results.
\end{abstract}

\section{Introduction}

The subject of fractional differential equations has recently evolved as an interesting and popular field of research. In fact, fractional derivatives provide an excellent tool for the description of memory and hereditary properties of various materials and processes. More and more researchers have found that fractional differential equations play important roles in many research areas, such as physics, chemical technology, population dynamics, biotechnology, and economics (see [1-4]). Hence, there are many literatures devoted to solving fractional differential equations through theoretical analysis or numerical methods (e.g., see [5-9]).

The theory of impulsive differential equations of integer order has found its extensive applications in realistic mathematical modeling of a wide variety of practical situations and has emerged as an important area of investigation in recent years. For the general theory and applications of impulsive differential equations, see [10-15] and so forth. However, impulsive differential equations of fractional order have not been much studied and many aspects of these equations are yet to be explored. For some recent work on impulsive fractional differential equations, we can refer to [16-24] and the references therein.
In this paper, we investigate the existence and uniqueness of solutions for fractional differential equations with fractional impulsive conditions

$$
\begin{aligned}
& { }^{c} D^{\alpha} x(t)=f(t, x(t)), \\
& t \in J:=[0, T], \quad t \neq t_{k}, \quad k=1,2, \ldots, m, \\
& \Delta x\left(t_{k}\right)=I_{k}\left(x\left(t_{k}^{-}\right)\right), \quad \Delta\left({ }^{c} D^{\gamma} x\left(t_{k}\right)\right)=I_{k}^{*}\left(x\left(t_{k}^{-}\right)\right), \\
& k=1,2, \ldots, m,
\end{aligned}
$$

and nonseparated boundary conditions

$$
\begin{gathered}
a_{1} x(0)+b_{1} x(T)=c_{1}, \quad a_{2} x^{\prime}(0)+b_{2} x^{\prime}(T)=c_{2}, \\
a_{1} x(0)+b_{1} x(T)=c_{1}, \\
a_{2}\left({ }^{c} D^{\gamma} x(0)\right)+b_{2}\left({ }^{c} D^{\gamma} x(T)\right)=c_{2},
\end{gathered}
$$

where ${ }^{c} D^{\alpha}$ is the Caputo fractional derivative of order $\alpha \epsilon$ $(1,2), 0<\gamma<1, f \in C(J \times \mathbb{R}, \mathbb{R}), I_{k}, I_{k}^{*} \in C(\mathbb{R}, \mathbb{R}), 0=t_{0}<$ $t_{1}<\cdots<t_{m}<t_{m+1}=T, \Delta x\left(t_{k}\right)=x\left(t_{k}^{+}\right)-x\left(t_{k}^{-}\right)$with $x\left(t_{k}^{+}\right)=$ $\lim _{\epsilon \rightarrow 0^{+}} x\left(t_{k}+\epsilon\right), x\left(t_{k}^{-}\right)=\lim _{\epsilon \rightarrow 0^{-}} x\left(t_{k}+\epsilon\right)$ representing the right and left limits of $x(t)$ at $t=t_{k}, \Delta\left({ }^{c} D^{\gamma} x\left(t_{k}\right)\right)$ has a similar meaning for ${ }^{c} D^{\gamma} x\left(t_{k}\right)$, and $a_{i}, b_{i}, c_{i}, i=1,2$, are real constants 
such that $\left(a_{1}+b_{1}\right)\left(a_{2}+b_{2}\right) \neq 0$ for $(2)$ and $\left(a_{1}+b_{1}\right) b_{2} \neq 0$ for (3).

We note that, as pointed out in the papers [22-24], the concept of piecewise continuous solutions used in some already published works to handle the impulsive fractional differential equations is not appropriate (see counterexamples given in Lemma 3.1 of [22], Section 1 in [23], and Section 3 in [24]). The papers on this topic cited above except [22] all deal with the Caputo derivative and the impulsive conditions only involve integer order derivatives. Here we study the fractional differential equations with fractional impulsive conditions and nonseparated boundary conditions [25-27].

If we let $a_{1}=b_{1}=1, a_{2}=b_{2}=1$, and $c_{1}=c_{2}=$ 0 in boundary conditions (2) and (3), then they reduce to antiperiodic boundary conditions $x(0)=-x(T), x^{\prime}(0)=$ $-x^{\prime}(T)$ and $x(0)=-x(T),{ }^{c} D^{\gamma} x(0)=-{ }^{c} D^{\gamma} x(T)$.

The rest of the paper is organized as follows. In Section 2 we introduce some notations and definitions needed in the following sections and give the appropriate formula of solutions for our problems. In Section 3 we present the existence results for the problems (1), (2) and (1), (3). Two examples are presented in Section 4 to illustrate the results. Concluding remarks are provided in Section 5.

\section{Preliminaries}

Let us set $J_{0}=\left[0, t_{1}\right], J_{1}=\left(t_{1}, t_{2}\right], \ldots, J_{m-1}=\left(t_{m-1}, t_{m}\right]$, $J_{m}=\left(t_{m}, t_{m+1}\right]$, and $J^{\prime}:=J \backslash\left\{t_{1}, t_{2}, \ldots, t_{m}\right\}$ and introduce the space $P C(J, \mathbb{R}):=\left\{u: J \rightarrow \mathbb{R} \mid u \in C\left(J_{k}, \mathbb{R}\right), k=\right.$ $0,1,2, \ldots, m$, and there exist $u\left(t_{k}^{+}\right)$and $u\left(t_{k}^{-}\right), k=1,2, \ldots, m$, with $\left.u\left(t_{k}^{-}\right)=u\left(t_{k}\right)\right\}$. It is clear that $P C(J, \mathbb{R})$ is a Banach space with the norm $\|u\|=\sup \{|u(t)|: t \in J\}$.

Definition 1 (see [4]). The Riemann-Liouville fractional integral of order $q$ for a function $f$ is defined as

$$
I^{q} f(t)=\frac{1}{\Gamma(q)} \int_{0}^{t}(t-s)^{q-1} f(s) d s, \quad q>0,
$$

provided the integral exists.

Definition 2 (see [4]). For a continuous function $f$, the Caputo derivative of order $q$ is defined as

$$
\begin{array}{r}
{ }^{c} D^{q} f(t)=\frac{1}{\Gamma(n-q)} \int_{0}^{t}(t-s)^{n-q-1} f^{(n)}(s) d s, \\
n-1<q<n, n=[q]+1,
\end{array}
$$

where $[q]$ denotes the integer part of the real number $q$.

Lemma 3 (see [4]). Let $\alpha>0$; then the differential equation

$$
{ }^{c} D^{\alpha} h(t)=0
$$

has solutions $h(t)=c_{0}+c_{1} t+c_{2} t^{2}+\cdots+c_{n-1} t^{n-1}$ and

$$
I^{\alpha c} D^{\alpha} h(t)=h(t)+c_{0}+c_{1} t+c_{2} t^{2}+\cdots+c_{n-1} t^{n-1},
$$

where $c_{i} \in \mathbb{R}, i=0,1,2, \ldots, n-1, n=[\alpha]+1$.
Definition 4. A function $x \in P C(J, \mathbb{R})$ with its $\alpha$-derivative existing on $J^{\prime}$ is said to be a solution of the problems (1), (2) (or the problems (1), (3)), if $x$ satisfies the equation ${ }^{c} D^{\alpha} x(t)=$ $f(t, x(t))$ on $J^{\prime}$, the impulsive conditions

$$
\begin{aligned}
\Delta x\left(t_{k}\right)=I_{k}\left(x\left(t_{k}^{-}\right)\right), \quad \Delta\left({ }^{c} D^{\gamma} x\left(t_{k}\right)\right) & =I_{k}^{*}\left(x\left(t_{k}^{-}\right)\right), \\
k & =1,2, \ldots, m,
\end{aligned}
$$

and the nonseparated boundary conditions (2) (or (3)).

Lemma 5. Let $y \in P C(J, \mathbb{R})$. A function $x$ is a solution of the fractional integral equation

$$
\begin{aligned}
& x(t) \\
& \left\{\begin{array}{l}
\int_{0}^{t} \frac{(t-s)^{\alpha-1}}{\Gamma(\alpha)} y(s) d s+d_{0}+e_{0} t, \quad t \in J_{0} ; \\
\int_{0}^{t} \frac{(t-s)^{\alpha-1}}{\Gamma(\alpha)} y(s) d s+d_{0}+I_{1}\left(x\left(t_{1}^{-}\right)\right) \\
-\Gamma(2-\gamma) t_{1}^{\gamma} I_{1}^{*}\left(x\left(t_{1}^{-}\right)\right) \\
+e_{0} t+\Gamma(2-\gamma) t_{1}^{\gamma-1} I_{1}^{*}\left(x\left(t_{1}^{-}\right)\right) t, \quad t \in J_{1} ; \\
\quad \vdots \\
\begin{array}{c}
t \\
0
\end{array} \\
-\Gamma(2-\gamma) \sum_{i=1}^{k} t_{i}^{\gamma} I_{i}^{*}\left(x\left(t_{i}^{-}\right)\right)+e_{0} t \\
+\Gamma(2-\gamma) t \sum_{i=1}^{k} t_{i}^{\gamma-1} I_{i}^{*}\left(x\left(t_{i}^{-}\right)\right), \quad t \in J_{k}, \\
\quad k=1,2, \ldots, m,
\end{array}\right.
\end{aligned}
$$

where

$$
\begin{aligned}
& d_{0}= \frac{c_{1}-b_{1} \int_{0}^{T}\left((T-s)^{\alpha-1} / \Gamma(\alpha)\right) y(s) d s-b_{1} A}{a_{1}+b_{1}} \\
&-\left(b_{1} c_{2} T+a_{2} b_{1} T B\right. \\
&\left.-b_{1} b_{2} T \int_{0}^{T} \frac{(T-s)^{\alpha-2}}{\Gamma(\alpha-1)} y(s) d s\right) \\
& \quad \times\left(\left(a_{1}+b_{1}\right)\left(a_{2}+b_{2}\right)\right)^{-1}, \\
& e_{0}=\frac{c_{2}-b_{2} \int_{0}^{T}\left((T-s)^{\alpha-2} / \Gamma(\alpha-1)\right) y(s) d s-b_{2} B}{a_{2}+b_{2}}, \\
& A=\sum_{i=1}^{m} I_{i}\left(x\left(t_{i}^{-}\right)\right)-\Gamma(2-\gamma) \sum_{i=1}^{m} t_{i}^{\gamma} I_{i}^{*}\left(x\left(t_{i}^{-}\right)\right), \\
& B=\Gamma^{m}(2-\gamma) \sum_{i=1}^{m} t_{i}^{\gamma-1} I_{i}^{*}\left(x\left(t_{i}^{-}\right)\right)
\end{aligned}
$$


if and only if $x$ is a solution of the impulsive fractional boundary value problem

$$
\begin{array}{r}
{ }^{c} D^{\alpha} x(t)=y(t), \quad t \in J^{\prime}, 1<\alpha<2, \\
\Delta x\left(t_{k}\right)=I_{k}\left(x\left(t_{k}^{-}\right)\right), \quad \Delta\left({ }^{c} D^{\gamma} x\left(t_{k}\right)\right)=I_{k}^{*}\left(x\left(t_{k}^{-}\right)\right), \\
k=1,2, \ldots, m, \\
a_{1} x(0)+b_{1} x(T)=c_{1}, \quad a_{2} x^{\prime}(0)+b_{2} x^{\prime}(T)=c_{2} .
\end{array}
$$

Proof. For $1<\alpha<2$, by Lemma 3, we know that a general solution of the equation ${ }^{c} D^{\alpha} x(t)=y(t)$ on each interval $J_{k}$ $(k=0,1,2, \ldots, m)$ is given by

$$
\begin{aligned}
x(t) & =I^{\alpha} y(t)+d_{k}+e_{k} t \\
& =\int_{0}^{t} \frac{(t-s)^{\alpha-1}}{\Gamma(\alpha)} y(s) d s+d_{k}+e_{k} t, \quad t \in J_{k},
\end{aligned}
$$

where $d_{k}$ and $e_{k} \in \mathbb{R}$ are arbitrary constants. Then we have

$$
x^{\prime}(t)=\int_{0}^{t} \frac{(t-s)^{\alpha-2}}{\Gamma(\alpha-1)} y(s) d s+e_{k}, \quad t \in J_{k} .
$$

Since ${ }^{c} D^{\gamma} C=0(C$ is a constant $),{ }^{c} D^{\gamma} t=t^{1-\gamma} / \Gamma(2-\gamma)$, and ${ }^{c} D^{\gamma} I^{\alpha} y(t)=I^{\alpha-\gamma} y(t)$ (see [4]), then from (13), we have

$$
{ }^{c} D^{\gamma} x(t)=\int_{0}^{t} \frac{(t-s)^{\alpha-\gamma-1}}{\Gamma(\alpha-\gamma)} y(s) d s+\frac{e_{k} t^{1-\gamma}}{\Gamma(2-\gamma)}, \quad t \in J_{k} .
$$

Applying the boundary conditions of (12), we get ( since $0 \in J_{0}$ and $T \in J_{m}$ )

$$
\begin{gathered}
a_{1} \times d_{0}+b_{1} \times\left(\int_{0}^{T} \frac{(T-s)^{\alpha-1}}{\Gamma(\alpha)} y(s) d s+d_{m}+e_{m} T\right)=c_{1}, \\
a_{2} \times e_{0}+b_{2} \times\left(\int_{0}^{T} \frac{(T-s)^{\alpha-2}}{\Gamma(\alpha-1)} y(s) d s+e_{m}\right)=c_{2} .
\end{gathered}
$$

Next using the impulsive conditions in (12), we obtain that, for $k=1,2, \ldots, m$,

$$
\begin{gathered}
d_{k}-d_{k-1}+\left(e_{k}-e_{k-1}\right) t_{k}=I_{k}\left(x\left(t_{k}^{-}\right)\right), \\
\left(e_{k}-e_{k-1}\right) \frac{t_{k}^{1-\gamma}}{\Gamma(2-\gamma)}=I_{k}^{*}\left(x\left(t_{k}^{-}\right)\right) .
\end{gathered}
$$

That is to say, we have, for $k=1,2, \ldots, m$,

$$
\begin{gathered}
d_{k}=d_{0}+\sum_{i=1}^{k} I_{i}\left(x\left(t_{i}^{-}\right)\right)-\Gamma(2-\gamma) \sum_{i=1}^{k} t_{i}^{\gamma} I_{i}^{*}\left(x\left(t_{i}^{-}\right)\right), \\
e_{k}=e_{0}+\Gamma(2-\gamma) \sum_{i=1}^{k} t_{i}^{\gamma-1} I_{i}^{*}\left(x\left(t_{i}^{-}\right)\right) .
\end{gathered}
$$

Now the above two equations together with (16) imply that

$$
\begin{aligned}
& d_{0}= \frac{c_{1}-b_{1} \int_{0}^{T}\left((T-s)^{\alpha-1} / \Gamma(\alpha)\right) y(s) d s-b_{1} A}{a_{1}+b_{1}} \\
&-\left(b_{1} c_{2} T+a_{2} b_{1} T B\right. \\
&\left.-b_{1} b_{2} T \int_{0}^{T} \frac{(T-s)^{\alpha-2}}{\Gamma(\alpha-1)} y(s) d s\right) \\
& \quad \times\left(\left(a_{1}+b_{1}\right)\left(a_{2}+b_{2}\right)\right)^{-1}, \\
& e_{0}=\frac{c_{2}-b_{2} \int_{0}^{T}\left((T-s)^{\alpha-2} / \Gamma(\alpha-1)\right) y(s) d s-b_{2} B}{a_{2}+b_{2}},
\end{aligned}
$$

where

$$
\begin{aligned}
& A=\sum_{i=1}^{m} I_{i}\left(x\left(t_{i}^{-}\right)\right)-\Gamma(2-\gamma) \sum_{i=1}^{m} t_{i}^{\gamma} I_{i}^{*}\left(x\left(t_{i}^{-}\right)\right), \\
& B=\Gamma(2-\gamma) \sum_{i=1}^{m} t_{i}^{\gamma-1} I_{i}^{*}\left(x\left(t_{i}^{-}\right)\right) .
\end{aligned}
$$

Hence, for $k=0,1,2, \ldots, m$, we have

$$
\begin{aligned}
d_{k}+e_{k} t= & d_{0}+\sum_{i=1}^{k} I_{i}\left(x\left(t_{i}^{-}\right)\right)-\Gamma(2-\gamma) \sum_{i=1}^{k} t_{i}^{\gamma} I_{i}^{*}\left(x\left(t_{i}^{-}\right)\right) \\
& +e_{0} t+\Gamma(2-\gamma) t \sum_{i=1}^{k} t_{i}^{\gamma-1} I_{i}^{*}\left(x\left(t_{i}^{-}\right)\right) .
\end{aligned}
$$

Substituting the value of $d_{0}$ and $e_{0}$ in (21), and by (13), we get the fractional integral equation (9).

Conversely, assume that $x$ satisfies the fractional integral equation (9); that is, for $t \in J_{k}, k=0,1,2, \ldots, m$, we have

$$
\begin{aligned}
x(t)= & \int_{0}^{t} \frac{(t-s)^{\alpha-1}}{\Gamma(\alpha)} y(s) d s+d_{0}+\sum_{i=1}^{k} I_{i}\left(x\left(t_{i}^{-}\right)\right) \\
& -\Gamma(2-\gamma) \sum_{i=1}^{k} t_{i}^{\gamma} I_{i}^{*}\left(x\left(t_{i}^{-}\right)\right) \\
& +e_{0} t+\Gamma(2-\gamma) t \sum_{i=1}^{k} t_{i}^{\gamma-1} I_{i}^{*}\left(x\left(t_{i}^{-}\right)\right), \\
x^{\prime}(t)= & \int_{0}^{t} \frac{(t-s)^{\alpha-2}}{\Gamma(\alpha-1)} y(s) d s \\
& +e_{0}+\Gamma(2-\gamma) \sum_{i=1}^{k} t_{i}^{\gamma-1} I_{i}^{*}\left(x\left(t_{i}^{-}\right)\right) .
\end{aligned}
$$

Since $1<\alpha<2$, we have ${ }^{c} D^{\alpha} C=0$ ( $C$ is a constant) and ${ }^{c} D^{\alpha} t=0$. Using the fact that ${ }^{c} D^{\alpha}$ is the left inverse of $I^{\alpha}$, we get

$$
{ }^{c} D^{\alpha} x(t)=y(t), \quad t \in J^{\prime},
$$


which means that $x$ satisfies the first equation of the impulsive fractional boundary value problem (12). Next we will verify that $x$ satisfies the impulsive conditions. Taking fractional derivative ${ }^{c} D^{\gamma}$ of (22), we have, for $t \in J_{k}$,

$$
\begin{aligned}
{ }^{c} D^{\gamma} x(t)= & \int_{0}^{t} \frac{(t-s)^{\alpha-\gamma-1}}{\Gamma(\alpha-\gamma)} y(s) d s \\
& +\frac{e_{0} t^{1-\gamma}}{\Gamma(2-\gamma)}+t^{1-\gamma} \sum_{i=1}^{k} t_{i}^{\gamma-1} I_{i}^{*}\left(x\left(t_{i}^{-}\right)\right) .
\end{aligned}
$$

From (22), we obtain

$$
\begin{aligned}
x\left(t_{k}^{+}\right)= & \int_{0}^{t_{k}} \frac{\left(t_{k}-s\right)^{\alpha-1}}{\Gamma(\alpha)} y(s) d s+d_{0}+\sum_{i=1}^{k} I_{i}\left(x\left(t_{i}^{-}\right)\right) \\
& -\Gamma(2-\gamma) \sum_{i=1}^{k} t_{i}^{\gamma} I_{i}^{*}\left(x\left(t_{i}^{-}\right)\right)+e_{0} t_{k} \\
& +\Gamma(2-\gamma) t_{k} \sum_{i=1}^{k} t_{i}^{\gamma-1} I_{i}^{*}\left(x\left(t_{i}^{-}\right)\right), \\
x\left(t_{k}^{-}\right)= & \int_{0}^{t_{k}} \frac{\left(t_{k}-s\right)^{\alpha-1}}{\Gamma(\alpha)} y(s) d s+d_{0}+\sum_{i=1}^{k-1} I_{i}\left(x\left(t_{i}^{-}\right)\right) \\
& -\Gamma(2-\gamma) \sum_{i=1}^{k-1} t_{i}^{\gamma} I_{i}^{*}\left(x\left(t_{i}^{-}\right)\right)+e_{0} t_{k} \\
& +\Gamma(2-\gamma) t_{k} \sum_{i=1}^{k-1} t_{i}^{\gamma-1} I_{i}^{*}\left(x\left(t_{i}^{-}\right)\right) .
\end{aligned}
$$

The two equations above imply that, for $k=1,2, \ldots, m$,

$$
\begin{aligned}
\Delta x\left(t_{k}\right)= & I_{k}\left(x\left(t_{k}^{-}\right)\right)-\Gamma(2-\gamma) t_{k}^{\gamma} I_{k}^{*}\left(x\left(t_{k}^{-}\right)\right) \\
& +\Gamma(2-\gamma) t_{k} t_{k}^{\gamma-1} I_{k}^{*}\left(x\left(t_{k}^{-}\right)\right)=I_{k}\left(x\left(t_{k}^{-}\right)\right) .
\end{aligned}
$$

Similarly, from (25), we have

$$
\begin{aligned}
{ }^{c} D^{\gamma} x\left(t_{k}^{+}\right)= & \int_{0}^{t_{k}} \frac{\left(t_{k}-s\right)^{\alpha-\gamma-1}}{\Gamma(\alpha-\gamma)} y(s) d s+\frac{e_{0} t_{k}^{1-\gamma}}{\Gamma(2-\gamma)} \\
& +t_{k}^{1-\gamma} \sum_{i=1}^{k} t_{i}^{\gamma-1} I_{i}^{*}\left(x\left(t_{i}^{-}\right)\right), \\
{ }^{c} D^{\gamma} x\left(t_{k}^{-}\right)= & \int_{0}^{t_{k}} \frac{\left(t_{k}-s\right)^{\alpha-\gamma-1}}{\Gamma(\alpha-\gamma)} y(s) d s \\
& +\frac{e_{0} t_{k}^{1-\gamma}}{\Gamma(2-\gamma)}+t_{k}^{1-\gamma} \sum_{i=1}^{k-1} t_{i}^{\gamma-1} I_{i}^{*}\left(x\left(t_{i}^{-}\right)\right) .
\end{aligned}
$$

Therefore, for $k=1,2, \ldots, m$, we have

$$
\Delta\left({ }^{c} D^{\gamma} x\left(t_{k}\right)\right)=t_{k}^{1-\gamma} t_{k}^{\gamma-1} I_{k}^{*}\left(x\left(t_{k}^{-}\right)\right)=I_{k}^{*}\left(x\left(t_{k}^{-}\right)\right) .
$$

Finally, it follows from (22) and (23) that (since $0 \in J_{0}, T \in$ $\left.J_{m}\right)$

$$
\begin{gathered}
x(0)=d_{0}, \\
x(T)=\int_{0}^{T} \frac{(T-s)^{\alpha-1}}{\Gamma(\alpha)} y(s) d s+d_{0}+A+e_{0} T+T B, \\
x^{\prime}(0)=e_{0}, \\
x^{\prime}(T)=\int_{0}^{T} \frac{(T-s)^{\alpha-2}}{\Gamma(\alpha-1)} y(s) d s+e_{0}+B .
\end{gathered}
$$

Hence, we get

$$
\begin{aligned}
& a_{1} x(0)+b_{1} x(T) \\
& =a_{1} d_{0}+b_{1}\left(\int_{0}^{T} \frac{(T-s)^{\alpha-1}}{\Gamma(\alpha)} y(s) d s+d_{0}+A+e_{0} T+T B\right) \\
& =c_{1}+b_{1} T B+b_{1} e_{0} T \\
& \quad-\left(b_{1} c_{2} T+a_{2} b_{1} T B\right. \\
& \left.\quad-b_{1} b_{2} T \int_{0}^{T} \frac{(T-s)^{\alpha-2}}{\Gamma(\alpha-1)} y(s) d s\right) \\
& \quad \times\left(a_{2}+b_{2}\right)^{-1}=c_{1}, \\
& a_{2} x^{\prime}(0)+b_{2} x^{\prime}(T) \\
& =a_{2} e_{0}+b_{2}\left(\int_{0}^{T} \frac{(T-s)^{\alpha-2}}{\Gamma(\alpha-1)} y(s) d s+e_{0}+B\right)=c_{2} .
\end{aligned}
$$

Therefore, $x$ given by (9) satisfies the impulsive fractional boundary value problem (12). The proof is complete.

Lemma 6. Let $y \in P C(J, \mathbb{R})$. A function $x$ is a solution of the fractional integral equation

$$
\left\{\begin{array}{c}
\int_{0}^{t} \frac{(t-s)^{\alpha-1}}{\Gamma(\alpha)} y(s) d s+d_{0}+e_{0} t, \quad t \in J_{0} ; \\
\int_{0}^{t} \frac{(t-s)^{\alpha-1}}{\Gamma(\alpha)} y(s) d s+d_{0}+I_{1}\left(x\left(t_{1}^{-}\right)\right) \\
-\Gamma(2-\gamma) t_{1}^{\gamma} I_{1}^{*}\left(x\left(t_{1}^{-}\right)\right) \\
+e_{0} t+\Gamma(2-\gamma) t_{1}^{\gamma-1} I_{1}^{*}\left(x\left(t_{1}^{-}\right)\right) t, \quad t \in J_{1} ; \\
\vdots \\
\int_{0}^{t} \frac{(t-s)^{\alpha-1}}{\Gamma(\alpha)} y(s) d s+d_{0}+\sum_{i=1}^{k} I_{i}\left(x\left(t_{i}^{-}\right)\right) \\
-\Gamma(2-\gamma) \sum_{i=1}^{k} t_{i}^{\gamma} I_{i}^{*}\left(x\left(t_{i}^{-}\right)\right)+e_{0} t \\
+\Gamma(2-\gamma) t \sum_{i=1}^{k} t_{i}^{\gamma-1} I_{i}^{*}\left(x\left(t_{i}^{-}\right)\right), \quad t \in J_{k}, \\
k=1,2, \ldots, m,
\end{array}\right.
$$


where

$$
\begin{gathered}
d_{0}=-\frac{b_{1}}{a_{1}+b_{1}}(C+A)+\frac{c_{1} b_{2}-b_{1} c_{2} T^{\gamma} \Gamma(2-\gamma)}{\left(a_{1}+b_{1}\right) b_{2}}, \\
e_{0}=-\frac{\Gamma(2-\gamma)}{T^{1-\gamma}}\left(\int_{0}^{T} \frac{(T-s)^{\alpha-\gamma-1}}{\Gamma(\alpha-\gamma)} y(s) d s-\frac{c_{2}}{b_{2}}\right)-B
\end{gathered}
$$

with $A$ and $B$ defined by (11) and

$$
\begin{aligned}
C= & \int_{0}^{T} \frac{(T-s)^{\alpha-1}}{\Gamma(\alpha)} y(s) d s \\
& -T^{\gamma} \Gamma(2-\gamma) \int_{0}^{T} \frac{(T-s)^{\alpha-\gamma-1}}{\Gamma(\alpha-\gamma)} y(s) d s,
\end{aligned}
$$

if and only if $x$ is a solution of the impulsive fractional boundary value problem

$$
\begin{gathered}
{ }^{c} D^{\alpha} x(t)=y(t), \quad t \in J^{\prime}, 1<\alpha<2, \\
\Delta x\left(t_{k}\right)=I_{k}\left(x\left(t_{k}^{-}\right)\right), \quad \Delta\left({ }^{c} D^{\gamma} x\left(t_{k}\right)\right)=I_{k}^{*}\left(x\left(t_{k}^{-}\right)\right), \\
k=1,2, \ldots, m, \\
a_{1} x(0)+b_{1} x(T)=c_{1}, \\
a_{2}\left({ }^{c} D^{\gamma} x(0)\right)+b_{2}\left({ }^{c} D^{\gamma} x(T)\right)=c_{2} .
\end{gathered}
$$

Proof. The proof is similar to that of Lemma 5. Let the notations be given as in the proof of Lemma 5. Applying the boundary conditions in (35), from the relations (13), (15), and (17), we have

$$
\begin{aligned}
& a_{1} \times d_{0}+b_{1} \times\left(\int_{0}^{T} \frac{(T-s)^{\alpha-1}}{\Gamma(\alpha)} y(s) d s+d_{m}+e_{m} T\right)=c_{1}, \\
& a_{2} \times 0+b_{2} \times\left(\int_{0}^{T} \frac{(T-s)^{\alpha-\gamma-1}}{\Gamma(\alpha-\gamma)} y(s) d s+\frac{e_{m} T^{1-\gamma}}{\Gamma(2-\gamma)}\right)=c_{2} .
\end{aligned}
$$

After a direct computation, we obtain that

$$
\begin{gathered}
d_{0}=-\frac{b_{1}}{a_{1}+b_{1}}(C+A)+\frac{c_{1} b_{2}-b_{1} c_{2} T^{\gamma} \Gamma(2-\gamma)}{\left(a_{1}+b_{1}\right) b_{2}}, \\
e_{0}=-\frac{\Gamma(2-\gamma)}{T^{1-\gamma}}\left(\int_{0}^{T} \frac{(T-s)^{\alpha-\gamma-1}}{\Gamma(\alpha-\gamma)} y(s) d s-\frac{c_{2}}{b_{2}}\right)-B
\end{gathered}
$$

with $A$ and $B$ defined by (11) and

$$
\begin{aligned}
C= & \int_{0}^{T} \frac{(T-s)^{\alpha-1}}{\Gamma(\alpha)} y(s) d s \\
& -T^{\gamma} \Gamma(2-\gamma) \int_{0}^{T} \frac{(T-s)^{\alpha-\gamma-1}}{\Gamma(\alpha-\gamma)} y(s) d s .
\end{aligned}
$$

The remaining part of proof is the same as that of Lemma 5.
Remark 7. We note that the solution expression (32) of the problem (35) does not depend on the parameter $a_{2}$ appearing in the boundary conditions. Thus, by Lemma 6 , we conclude that the parameter $a_{2}$ is of arbitrary nature of the problem (35).

Remark 8. Our approach for the construction of solutions for impulsive fractional differential equations is general, which provides an effective way to deal with such problems. Taking the problem (1) for example, on each interval $J_{k}$, we use

$$
x(t)=\int_{0}^{t} \frac{(t-s)^{\alpha-1}}{\Gamma(\alpha)} f(s, x(s)) d s+d_{k}+e_{k} t
$$

instead of

$$
x(t)=\int_{t_{k}}^{t} \frac{(t-s)^{\alpha-1}}{\Gamma(\alpha)} f(s, x(s)) d s+d_{k}+e_{k}\left(t-t_{k}\right) .
$$

From the counterexamples given in Lemma 3.1 of [22], Section 1 in [23], and Section 3 in [24], we know that if the case (II) was chosen to construct solutions, the solution formula obtained in the fractional integral equation form is not equivalent to the original impulsive fractional differential equation. This is the main difference between impulsive fractional differential equations and impulsive ordinary differential equations. Observe that fractional calculus has memory property.

Theorem 9 (nonlinear alternative of Leray-Schauder type [28]). Let $X$ be a Banach space, $C$ a nonempty convex subset of $X$, and $U$ a nonempty open subset of $C$ with $0 \in U$. Suppose that $P: \bar{U} \rightarrow C$ is a continuous and compact map. Then either (a) $P$ has a fixed point in $\bar{U}$ or (b) there exist a $x \in \partial U$ (the boundary of $U$ ) and $\lambda \in(0,1)$ with $x=\lambda P(x)$.

Theorem 10 (Schaefer fixed point theorem [29]). Let X be a normed space and $P$ a continuous mapping of $X$ into $X$ which is compact on each bounded subset $B$ of $X$. Then either (I) the equation $x=\lambda P x$ has a solution for $\lambda=1$ or (II) the set of all such solutions $x$, for $0<\lambda<1$, is unbounded.

\section{Main Results}

This section deals with the existence and uniqueness of solutions for the problem (1), (2) and the problem (1), (3).

First we study the existence results for the problem (1), (2). In view of Lemma 5 , we define an operator $F: P C(J, \mathbb{R}) \rightarrow$ $P C(J, \mathbb{R})$ by

$$
\begin{aligned}
(F x)(t)= & \int_{0}^{t} \frac{(t-s)^{\alpha-1}}{\Gamma(\alpha)} f(s, x(s)) d s+d_{0}^{x}+\sum_{i=1}^{k} I_{i}\left(x\left(t_{i}^{-}\right)\right) \\
& -\Gamma(2-\gamma) \sum_{i=1}^{k} t_{i}^{\gamma} I_{i}^{*}\left(x\left(t_{i}^{-}\right)\right)+e_{0}^{x} t
\end{aligned}
$$




$$
\begin{aligned}
&+\Gamma(2-\gamma) t \sum_{i=1}^{k} t_{i}^{\gamma-1} I_{i}^{*}\left(x\left(t_{i}^{-}\right)\right) \\
& t \in J_{k}, \quad k=0,1,2, \ldots, m
\end{aligned}
$$

where

$$
\begin{aligned}
& d_{0}^{x}= \frac{c_{1}-b_{1} \int_{0}^{T}\left((T-s)^{\alpha-1} / \Gamma(\alpha)\right) f(s, x(s)) d s-b_{1} A^{x}}{a_{1}+b_{1}} \\
&-\left(b_{1} c_{2} T+a_{2} b_{1} T B^{x}-b_{1} b_{2} T\right. \\
&\left.\times \int_{0}^{T} \frac{(T-s)^{\alpha-2}}{\Gamma(\alpha-1)} f(s, x(s)) d s\right) \\
& e_{0}^{x}=\frac{c_{2}-b_{2} \int_{0}^{T}\left((T-s)^{\alpha-2} / \Gamma(\alpha-1)\right) f(s, x(s)) d s-b_{2} B^{x}}{a_{2}+b_{2}}, \\
& A^{x}=\sum_{i=1}^{m} I_{i}\left(x\left(t_{i}^{-}\right)\right)-\Gamma(2-\gamma) \sum_{i=1}^{m} t_{i}^{\gamma} I_{i}^{*}\left(x\left(t_{i}^{-}\right)\right), \\
& B^{x}=\Gamma(2-\gamma) \sum_{i=1}^{m} t_{i}^{\gamma-1} I_{i}^{*}\left(x\left(t_{i}^{-}\right)\right) .
\end{aligned}
$$

Here $d_{0}^{x}, e_{0}^{x}, A^{x}$, and $B^{x}$ mean that $d_{0}, e_{0}, A$, and $B$ defined in Lemma 5 are related to $x \in P C(J, \mathbb{R})$. It is obvious that $F$ is well defined because of the continuity of $f, I_{k}$, and $I_{k}^{*}$ and that the problem (1), (2) has solutions if and only if the operator equation $F x=x$ has fixed points.

For the sake of convenience, we set

$$
\Delta=\left(a_{1}+b_{1}\right)\left(a_{2}+b_{2}\right) \text {. }
$$

Lemma 11. The operator $F: P C(J, \mathbb{R}) \rightarrow P C(J, \mathbb{R})$ defined by (39) is completely continuous.

Proof. Since $f, I_{k}$, and $I_{k}^{*}$ are continuous, it is easy to check that $F$ is continuous on $P C(J, \mathbb{R})$.

Let $B \subseteq P C(J, \mathbb{R})$ be bounded; then there exist positive constants $N_{i}, i=1,2,3$, such that $|f(t, x(t))| \leq N_{1}$, $\left|I_{k}\left(x\left(t_{k}^{-}\right)\right)\right| \leq N_{2}$, and $\left|I_{k}^{*}\left(x\left(t_{k}^{-}\right)\right)\right| \leq N_{3}$, for all $t \in J, x \in B$, $k=1,2, \ldots, m$. Thus, for $x \in B$ and $t \in J$, we have

$$
\begin{aligned}
|(F x)(t)| \leq & \frac{N_{1} T^{\alpha}}{\Gamma(\alpha+1)}+\left|d_{0}^{x}\right|+m N_{2}+\Gamma(2-\gamma) N_{3} \sum_{i=1}^{m} t_{i}^{\gamma} \\
& +\left|e_{0}^{x}\right| T+\Gamma(2-\gamma) T N_{3} \sum_{i=1}^{m} t_{i}^{\gamma-1}
\end{aligned}
$$

$$
\begin{aligned}
\left|d_{0}^{x}\right| \leq & \frac{\left|c_{1}\right|}{\left|a_{1}+b_{1}\right|}+\frac{\left|b_{1}\right|}{\left|a_{1}+b_{1}\right|} \\
& \times\left(\frac{N_{1} T^{\alpha}}{\Gamma(\alpha+1)}+m N_{2}+\Gamma(2-\gamma) N_{3} \sum_{i=1}^{m} t_{i}^{\gamma}\right) \\
& +\frac{\left|b_{1} c_{2}\right| T}{|\Delta|}+\frac{\left|a_{2} b_{1}\right| T}{|\Delta|} \Gamma(2-\gamma) N_{3} \sum_{i=1}^{m} t_{i}^{\gamma-1} \\
& +\frac{\left|b_{1} b_{2}\right| N_{1} T^{\alpha}}{|\Delta| \Gamma(\alpha)}, \\
\left|e_{0}^{x}\right| \leq & \frac{\left|c_{2}\right|}{\left|a_{2}+b_{2}\right|} \\
& +\frac{\left|b_{2}\right|}{\left|a_{2}+b_{2}\right|}\left(\frac{N_{1} T^{\alpha-1}}{\Gamma(\alpha)}+\Gamma(2-\gamma) N_{3} \sum_{i=1}^{m} t_{i}^{\gamma-1}\right)
\end{aligned}
$$

Therefore, we can deduce that, for all $x \in B$ and $t \in J$,

$$
\begin{aligned}
|(F x)(t)| \leq & \frac{N_{1} T^{\alpha}}{\Gamma(\alpha+1)}\left(1+\frac{\left|b_{1}\right|}{\left|a_{1}+b_{1}\right|}\right) \\
& +\frac{N_{1} T^{\alpha}}{\Gamma(\alpha)}\left(\frac{\left|b_{1} b_{2}\right|}{|\Delta|}+\frac{\left|b_{2}\right|}{\left|a_{2}+b_{2}\right|}\right) \\
& +m N_{2}\left(1+\frac{\left|b_{1}\right|}{\left|a_{1}+b_{1}\right|}\right) \\
& +\Gamma(2-\gamma) N_{3} \sum_{i=1}^{m} t_{i}^{\gamma}\left(1+\frac{\left|b_{1}\right|}{\left|a_{1}+b_{1}\right|}\right) \\
& +\Gamma(2-\gamma) T N_{3} \sum_{i=1}^{m} t_{i}^{\gamma-1}\left(1+\frac{\left|a_{2} b_{1}\right|}{|\Delta|}+\frac{\left|b_{2}\right|}{\left|a_{2}+b_{2}\right|}\right) \\
& +\frac{\left|c_{1}\right|}{\left|a_{1}+b_{1}\right|}+\frac{\left|b_{1} c_{2}\right| T}{|\Delta|}+\frac{\left|c_{2}\right| T}{\left|a_{2}+b_{2}\right|},
\end{aligned}
$$

which implies that the operator $F$ is uniformly bounded on B.

On the other hand, let $x \in B$ and, for any $\tau_{1}, \tau_{2} \in J_{k}$, $k=0,1,2, \ldots, m$, with $\tau_{1}<\tau_{2}$, we have

$$
\begin{aligned}
& \left|(F x)\left(\tau_{2}\right)-(F x)\left(\tau_{1}\right)\right| \\
& \leq \mid \int_{0}^{\tau_{2}} \frac{\left(\tau_{2}-s\right)^{\alpha-1}}{\Gamma(\alpha)} f(s, x(s)) d s \\
& \quad-\int_{0}^{\tau_{1}} \frac{\left(\tau_{1}-s\right)^{\alpha-1}}{\Gamma(\alpha)} f(s, x(s)) d s \mid \\
& \quad+\left|e_{0}^{x}\right|\left(\tau_{2}-\tau_{1}\right)+\Gamma(2-\gamma) \sum_{i=1}^{k} t_{i}^{\gamma-1}\left|I_{i}^{*}\left(x\left(t_{i}^{-}\right)\right)\right|\left(\tau_{2}-\tau_{1}\right)
\end{aligned}
$$




$$
\begin{aligned}
\leq & \frac{N_{1}\left(\tau_{2}^{\alpha}-\tau_{1}^{\alpha}\right)}{\Gamma(\alpha+1)}+\left|e_{0}^{x}\right|\left(\tau_{2}-\tau_{1}\right) \\
& +\Gamma(2-\gamma) N_{3} \sum_{i=1}^{k} t_{i}^{\gamma-1}\left(\tau_{2}-\tau_{1}\right) .
\end{aligned}
$$

From (43) and the above inequality, we deduce that $\mid(F x)\left(\tau_{2}\right)-$ $(F x)\left(\tau_{1}\right) \mid$ tends to zero as $\tau_{2} \rightarrow \tau_{1}$. This implies that $F$ is equicontinuous on the interval $J_{k}$. Hence, by PC-type ArzelaAscoli Theorem (see Theorem $2.1[15]$ ), the operator $F$ : $P C(J, \mathbb{R}) \rightarrow P C(J, \mathbb{R})$ is completely continuous.

(H1): (1) there exist $h \in L^{\infty}\left(J, \mathbb{R}^{+}\right)$and $\varphi:[0, \infty) \rightarrow$ $(0, \infty)$ continuous nondecreasing such that $|f(t, x)| \leq$ $h(t) \varphi(|x|)$ for $(t, x) \in J \times \mathbb{R} ;(2)$ there exist $\psi$ and $\psi^{*}:[0, \infty) \rightarrow(0, \infty)$ continuous nondecreasing such that $\left|I_{k}(x)\right| \leq \psi(|x|)$ and $\left|I_{k}^{*}(x)\right| \leq \psi^{*}(|x|)$ for all $x \in \mathbb{R}$ and $k=1,2, \ldots, m$.

Theorem 12. Let (H1) hold and there exists a constant $M>0$ such that

$$
\frac{M}{\|h\|_{L^{\infty}} \varphi(M) P+\Gamma(2-\gamma) \psi^{*}(M) R+\psi(M) Q+H}>1,
$$

where

$$
\begin{aligned}
P= & \frac{T^{\alpha}}{\Gamma(\alpha+1)}\left(1+\frac{\left|b_{1}\right|}{\left|a_{1}+b_{1}\right|}\right) \\
& +\frac{T^{\alpha}}{\Gamma(\alpha)}\left(\frac{\left|b_{1} b_{2}\right|}{|\Delta|}+\frac{\left|b_{2}\right|}{\left|a_{2}+b_{2}\right|}\right), \\
Q= & m\left(1+\frac{\left|b_{1}\right|}{\left|a_{1}+b_{1}\right|}\right), \\
H= & \frac{\left|c_{1}\right|}{\left|a_{1}+b_{1}\right|}+\frac{\left|b_{1} c_{2}\right| T}{|\Delta|}+\frac{\left|c_{2}\right| T}{\left|a_{2}+b_{2}\right|}, \\
R= & \left(1+\frac{\left|b_{1}\right|}{\left|a_{1}+b_{1}\right|}\right) \sum_{i=1}^{m} t_{i}^{\gamma} \\
& +T\left(1+\frac{\left|a_{2} b_{1}\right|}{|\Delta|}+\frac{\left|b_{2}\right|}{\left|a_{2}+b_{2}\right|}\right) \sum_{i=1}^{m} t_{i}^{\gamma-1} .
\end{aligned}
$$

Then the impulsive fractional boundary value problem (1), (2) has at least one solution on $J$.

Proof. We will show that the operator $F$ defined by (39) satisfies the assumptions of the nonlinear alternative of LeraySchauder type.

From Lemma 11, the operator $F: P C(J, \mathbb{R}) \rightarrow P C(J, \mathbb{R})$ is continuous and completely continuous.
Let $x \in P C(J, \mathbb{R})$ be such that $x(t)=\lambda(F x)(t)$ for some $\lambda \in(0,1)$. Then using the computations in the proof that $F$ maps bounded sets into bounded sets in Lemma 11, we have

$$
\begin{aligned}
|x(t)| \leq & \|h\|_{L^{\infty}} \varphi(\|x\|)\left[\frac{T^{\alpha}}{\Gamma(\alpha+1)}\left(1+\frac{\left|b_{1}\right|}{\left|a_{1}+b_{1}\right|}\right)\right. \\
& \left.\quad+\frac{T^{\alpha}}{\Gamma(\alpha)}\left(\frac{\left|b_{1} b_{2}\right|}{|\Delta|}+\frac{\left|b_{2}\right|}{\left|a_{2}+b_{2}\right|}\right)\right] \\
& +m \psi(\|x\|)\left(1+\frac{\left|b_{1}\right|}{\left|a_{1}+b_{1}\right|}\right) \\
& +\Gamma(2-\gamma) \psi^{*}(\|x\|)\left(1+\frac{\left|b_{1}\right|}{\left|a_{1}+b_{1}\right|}\right) \sum_{i=1}^{m} t_{i}^{\gamma} \\
& +\Gamma(2-\gamma) \psi^{*}(\|x\|) \\
& \times T\left(1+\frac{\left|a_{2} b_{1}\right|}{|\Delta|}+\frac{\left|b_{2}\right|}{\left|a_{2}+b_{2}\right|}\right) \sum_{i=1}^{m} t_{i}^{\gamma-1} \\
& +\frac{\left|c_{1}\right|}{\left|a_{1}+b_{1}\right|}+\frac{\left|b_{1} c_{2}\right| T}{|\Delta|}+\frac{\left|c_{2}\right| T}{\left|a_{2}+b_{2}\right|} \\
\leq & \|h\|_{L^{\infty}} \varphi(\|x\|) P+\psi(\|x\|) Q \\
& +\Gamma(2-\gamma) \psi^{*}(\|x\|) R+H .
\end{aligned}
$$

Consequently, we have

$$
\frac{\|x\|}{\|h\|_{L^{\infty}} \varphi(\|x\|) P+\Gamma(2-\gamma) \psi^{*}(\|x\|) R+\psi(\|x\|) Q+H} \leq 1 .
$$

Then, in view of condition (46), there exists $M>0$ such that $\|x\| \neq M$. Let us set

$$
U=\{x \in P C(J, \mathbb{R}):\|x\|<M\} .
$$

The operator $F: \bar{U} \rightarrow P C(J, \mathbb{R})$ is continuous and compact. From the choice of the set $U$, there is no $x \in \partial U$ such that $x=\lambda F x$ for some $\lambda \in(0,1)$. Therefore, by the nonlinear alternative of Leray-Schauder type (see Theorem 9), we deduce that $F$ has a fixed point $x$ in $\bar{U}$ which is a solution of the impulsive fractional boundary value problem (1), (2). The proof is complete.

(H2): there exist $h \in L^{\infty}\left(J, \mathbb{R}^{+}\right)$and positive constants $H_{1}$ and $H_{2}$ such that, for $t \in J, x \in \mathbb{R}, k=1,2, \ldots, m$,

$$
|f(t, x)| \leq h(t), \quad\left|I_{k}(x)\right| \leq H_{1}, \quad\left|I_{k}^{*}(x)\right| \leq H_{2} .
$$

Theorem 13. If (H2) holds, then the impulsive fractional boundary value problem (1), (2) has at least one solution on $J$. 
Proof. Lemma 11 tells us that the operator $F: P C(J, \mathbb{R}) \rightarrow$ $P C(J, \mathbb{R})$ defined by (39) is continuous and compact on each bounded subset $B$ of $P C(J, \mathbb{R})$.

Now let us show that the set $V=\{u \in P C(J, \mathbb{R}): u=$ $\lambda F u, 0<\lambda<1\}$ is bounded. Let $x \in V$; then $x=\lambda F x$ for some $0<\lambda<1$. For each $t \in J$, using the similar estimations given in Theorem 12, we have

$$
\begin{aligned}
|x(t)| \leq \| & \|\|_{L^{\infty}}\left[\frac{T^{\alpha}}{\Gamma(\alpha+1)}\left(1+\frac{\left|b_{1}\right|}{\left|a_{1}+b_{1}\right|}\right)\right. \\
& \left.+\frac{T^{\alpha}}{\Gamma(\alpha)}\left(\frac{\left|b_{1} b_{2}\right|}{|\Delta|}+\frac{\left|b_{2}\right|}{\left|a_{2}+b_{2}\right|}\right)\right] \\
& +m H_{1}\left(1+\frac{\left|b_{1}\right|}{\left|a_{1}+b_{1}\right|}\right) \\
& +\Gamma(2-\gamma) H_{2}\left(1+\frac{\left|b_{1}\right|}{\left|a_{1}+b_{1}\right|}\right) \sum_{i=1}^{m} t_{i}^{\gamma} \\
& +\Gamma(2-\gamma) H_{2} T\left(1+\frac{\left|a_{2} b_{1}\right|}{|\Delta|}+\frac{\left|b_{2}\right|}{\left|a_{2}+b_{2}\right|}\right) \sum_{i=1}^{m} t_{i}^{\gamma-1} \\
& +\frac{\left|c_{1}\right|}{\left|a_{1}+b_{1}\right|}+\frac{\left|b_{1} c_{2}\right| T}{|\Delta|}+\frac{\left|c_{2}\right| T}{\left|a_{2}+b_{2}\right|} .
\end{aligned}
$$

This implies that there exists some $\bar{C}>0$ such that $\|x\| \leq \bar{C}$ for all $x \in V$; that is, $V$ is bounded. Thus, by Theorem 10 , the operator $F$ has at least one fixed point. Hence the problem (1), (2) has at least one solution. The proof is completed.

(H3): there exist $h \in L^{\infty}\left(J, \mathbb{R}^{+}\right)$and positive constants $L$ and $L^{*}$ such that, for $t \in J, x, y \in \mathbb{R}, k=1,2, \ldots, m$,

$$
\begin{gathered}
|f(t, x)-f(t, y)| \leq h(t)|x-y|, \\
\left|I_{k}(x)-I_{k}(y)\right| \leq L|x-y|, \\
\left|I_{k}^{*}(x)-I_{k}^{*}(y)\right| \leq L^{*}|x-y| .
\end{gathered}
$$

Theorem 14. Let (H3) hold. Moreover,

$$
\begin{aligned}
& \left(\frac{\|h\|_{L^{\infty}} T^{\alpha}}{\Gamma(\alpha+1)}+m L+\Gamma(2-\gamma) L^{*} \sum_{i=1}^{m} t_{i}^{\gamma}\right)\left(1+\frac{\left|b_{1}\right|}{\left|a_{1}+b_{1}\right|}\right) \\
& +\Gamma(2-\gamma) T L^{*} \\
& \quad \times\left(1+\frac{\left|a_{2} b_{1}\right|}{|\Delta|}+\frac{\left|b_{2}\right|}{\left|a_{2}+b_{2}\right|}\right) \sum_{i=1}^{m} t_{i}^{\gamma-1} \\
& +\left(\frac{\left|b_{1} b_{2}\right|}{|\Delta|}+\frac{\left|b_{2}\right|}{\left|a_{2}+b_{2}\right|}\right) \frac{\|h\|_{L^{\infty}} T^{\alpha}}{\Gamma(\alpha)}<1 .
\end{aligned}
$$

Then the impulsive fractional boundary value problem (1), (2) has a unique solution on $\mathrm{J}$.
Proof. Let $x, y \in P C(J, \mathbb{R})$. Then, for each $t \in J$, we have

$$
\begin{aligned}
& |(F x)(t)-(F y)(t)| \\
& \leq \int_{0}^{t} \frac{(t-s)^{\alpha-1}}{\Gamma(\alpha)}|f(s, x(s))-f(s, y(s))| d s+\left|d_{0}^{x}-d_{0}^{y}\right| \\
& \quad+\sum_{i=1}^{m}\left|I_{i}\left(x\left(t_{i}^{-}\right)\right)-I_{i}\left(y\left(t_{i}^{-}\right)\right)\right| \\
& \quad+\Gamma(2-\gamma) \sum_{i=1}^{m} t_{i}^{\gamma}\left|I_{i}^{*}\left(x\left(t_{i}^{-}\right)\right)-I_{i}^{*}\left(y\left(t_{i}^{-}\right)\right)\right| \\
& \quad+\left|e_{0}^{x}-e_{0}^{y}\right| T \\
& \quad+\Gamma(2-\gamma) T \sum_{i=1}^{m} t_{i}^{\gamma-1}\left|I_{i}^{*}\left(x\left(t_{i}^{-}\right)\right)-I_{i}^{*}\left(y\left(t_{i}^{-}\right)\right)\right| .
\end{aligned}
$$

Since

$$
\begin{aligned}
\left|d_{0}^{x}-d_{0}^{y}\right| \leq & \frac{\left|b_{1}\right|}{\left|a_{1}+b_{1}\right|} \\
& \times\left(\frac{\|h\|_{L^{\infty}} T^{\alpha}}{\Gamma(\alpha+1)}+m L\right. \\
& \left.+\Gamma(2-\gamma) L^{*} \sum_{i=1}^{m} t_{i}^{\gamma}\right)\|x-y\| \\
& +\left(\frac{\left|a_{2} b_{1}\right|}{|\Delta|} \Gamma(2-\gamma) T L^{*} \sum_{i=1}^{m} t_{i}^{\gamma-1}\right. \\
\left|e_{0}^{x}-e_{0}^{y}\right| T \leq & \left.\frac{\left|b_{2}\right|}{\left|a_{2}+b_{2}\right|} \frac{\| b_{1} b_{2} \mid}{|\Delta|} \frac{\|h\|_{L^{\infty}} T^{\alpha}}{\Gamma(\alpha)}\right)\|x-y\|, \\
& \times\left(\frac{\|h\|_{L^{\infty}} T^{\alpha}}{\Gamma(\alpha)}+\Gamma(2-\gamma) T L^{*} \sum_{i=1}^{m} t_{i}^{\gamma-1}\right)\|x-y\|,
\end{aligned}
$$

then combining these two estimations with (55), we obtain

$$
\begin{aligned}
& \|F x-F y\| \\
& \leq\left[\left(\frac{\|h\|_{L^{\infty} T^{\alpha}}}{\Gamma(\alpha+1)}+m L+\Gamma(2-\gamma) L^{*} \sum_{i=1}^{m} t_{i}^{\gamma}\right)\right. \\
& \quad \times\left(1+\frac{\left|b_{1}\right|}{\left|a_{1}+b_{1}\right|}\right) \\
& +\Gamma(2-\gamma) T L^{*}\left(1+\frac{\left|a_{2} b_{1}\right|}{|\Delta|}+\frac{\left|b_{2}\right|}{\left|a_{2}+b_{2}\right|}\right) \sum_{i=1}^{m} t_{i}^{\gamma-1} \\
& \left.+\left(\frac{\left|b_{1} b_{2}\right|}{|\Delta|}+\frac{\left|b_{2}\right|}{\left|a_{2}+b_{2}\right|}\right) \frac{\|h\|_{L^{\infty}} T^{\alpha}}{\Gamma(\alpha)}\right]\|x-y\| .
\end{aligned}
$$


Therefore, by (54), the operator $F$ is a contraction mapping on $P C(J, \mathbb{R})$. Then it follows from Banach's fixed point theorem that the problems (1), (2) has a unique solution on $J$. This completes the proof.

Next we will state some existence results for the problems (1), (3) without proofs since these are similar to the ones obtained for the problems (1), (2) above.

Theorem 15. Let (H1) hold and there exists a constant $M>0$ such that

$$
\frac{M}{\|h\|_{L^{\infty}} \varphi(M) P_{1}+\Gamma(2-\gamma) \psi^{*}(M) R_{1}+\psi(M) Q_{1}+H_{1}}>1
$$

where

$$
\begin{aligned}
P_{1} & =\left(1+\frac{\left|b_{1}\right|}{\left|a_{1}+b_{1}\right|}\right)\left(\frac{T^{\alpha}}{\Gamma(\alpha+1)}+\frac{\Gamma(2-\gamma) T^{\alpha}}{\Gamma(\alpha-\gamma+1)}\right), \\
Q_{1} & =m\left(1+\frac{\left|b_{1}\right|}{\left|a_{1}+b_{1}\right|}\right), \\
R_{1} & =\left(1+\frac{\left|b_{1}\right|}{\left|a_{1}+b_{1}\right|}\right) \sum_{i=1}^{m} t_{i}^{\gamma}+2 T \sum_{i=1}^{m} t_{i}^{\gamma-1}, \\
H_{1} & =\frac{\left|c_{1} b_{2}-b_{1} c_{2} T^{\gamma} \Gamma(2-\gamma)\right|}{\left|\left(a_{1}+b_{1}\right) b_{2}\right|}+\frac{\Gamma(2-\gamma)\left|c_{2}\right| T^{\gamma}}{\left|b_{2}\right|} .
\end{aligned}
$$

Then the impulsive fractional boundary value problem (1), (3) has at least one solution on $J$.

Theorem 16. Let (H2) hold; then the impulsive fractional boundary value problem (1), (3) has at least one solution on J.

Theorem 17. Assume that (H3) holds. Moreover,

$$
\begin{gathered}
\left(1+\frac{\left|b_{1}\right|}{\left|a_{1}+b_{1}\right|}\right)\left[\frac{\|h\|_{L^{\infty}} T^{\alpha}}{\Gamma(\alpha+1)}+\frac{\|h\|_{L^{\infty}} \Gamma(2-\gamma) T^{\alpha}}{\Gamma(\alpha-\gamma+1)}\right. \\
\left.+m L+\Gamma(2-\gamma) L^{*} \sum_{i=1}^{m} t_{i}^{\gamma}\right] \\
+2 \Gamma(2-\gamma) T L^{*} \sum_{i=1}^{m} t_{i}^{\gamma-1}<1 .
\end{gathered}
$$

Then the impulsive fractional boundary value problem (1), (3) has a unique solution on $J$.

Remark 18. The results obtained in this paper can easily be generalized to the boundary value problems of impulsive fractional differential equations (1) with nonseparated integral boundary conditions

$$
\begin{gathered}
a_{1} x(0)+b_{1} x(T)=c_{1} \int_{0}^{T} g(s, x(s)) d s, \\
a_{2} x^{\prime}(0)+b_{2} x^{\prime}(T)=c_{2} \int_{0}^{T} h(s, x(s)) d s, \\
a_{1} x(0)+b_{1} x(T)=c_{1} \int_{0}^{T} g(s, x(s)) d s, \\
a_{2}\left({ }^{c} D^{\gamma} x(0)\right)+b_{2}\left({ }^{c} D^{\gamma} x(T)\right)=c_{2} \int_{0}^{T} h(s, x(s)) d s,
\end{gathered}
$$

where $g$ and $h:[0, T] \times \mathbb{R} \rightarrow \mathbb{R}$ are given continuous functions.

\section{Examples}

In this section, we give two simple examples to show the applicability of our results.

Example 1. Consider the following impulsive fractional BVP:

$$
\begin{gathered}
{ }^{c} D^{7 / 4} x(t)=\frac{\cos t}{(t+6)^{2}}(x(t)+\arctan x(t)), \\
t \in[0,1], t \neq \frac{1}{2}, \\
\Delta x\left(\frac{1}{2}\right)=\frac{\left|x\left(1 / 2^{-}\right)\right|}{\left(17+\left|x\left(1 / 2^{-}\right)\right|\right)}, \\
\Delta\left({ }^{c} D^{1 / 4} x\left(\frac{1}{2}\right)\right)=\frac{\left|x\left(1 / 2^{-}\right)\right|}{\left(20+\left|x\left(1 / 2^{-}\right)\right|\right)}, \\
3 x(0)+\frac{1}{3} x(1)=1, \\
2\left({ }^{c} D^{1 / 4} x(0)\right)+3\left({ }^{c} D^{1 / 4} x(1)\right)=\frac{1}{4} .
\end{gathered}
$$

Here $\alpha=7 / 4, \gamma=1 / 4, T=1, m=1, a_{1}=3, b_{1}=1 / 3$, $c_{1}=1, a_{2}=2, b_{2}=3$, and $c_{2}=1 / 4$. Clearly, we can take $h(t)=2 \cos t /(t+6)^{2}, L=1 / 17$, and $L^{*}=1 / 20$ such that the relations (53) hold. Moreover,

$$
\begin{aligned}
& \left(1+\frac{\left|b_{1}\right|}{\left|a_{1}+b_{1}\right|}\right)\left[\frac{\|h\|_{L^{\infty}} T^{\alpha}}{\Gamma(\alpha+1)}+\frac{\|h\|_{L^{\infty}} \Gamma(2-\gamma) T^{\alpha}}{\Gamma(\alpha-\gamma+1)}\right. \\
& \left.\quad+m L+\Gamma(2-\gamma) L^{*} \sum_{i=1}^{m} t_{i}^{\gamma}\right] \\
& +2 \Gamma(2-\gamma) T L^{*} \sum_{i=1}^{m} t_{i}^{\gamma-1} \\
& \approx \\
& \quad \frac{11}{10} \times\left(\frac{1.3131}{18}+\frac{1}{17}+0.0386\right)+0.1546 \\
& =0.3420<1 .
\end{aligned}
$$


Thus, all the assumptions of Theorem 17 are satisfied. Hence, by the conclusion of Theorem 17, the impulsive fractional $\operatorname{BVP}(62)$ has a unique solution on $[0,1]$.

Example 2. Consider the following impulsive fractional BVP:

$$
\begin{gathered}
{ }^{c} D^{3 / 2} x(t)=5 t^{2}+e^{-|x(t)|}+\sin x(t), \\
t \in[0,1], t \neq \frac{1}{4}, \\
\Delta x\left(\frac{1}{4}\right)=\frac{2\left|x\left(1 / 4^{-}\right)\right|}{\left(1+\left|x\left(1 / 4^{-}\right)\right|\right)} \\
\Delta\left({ }^{c} D^{1 / 2} x\left(\frac{1}{4}\right)\right)=\cos x\left(\frac{1^{-}}{4}\right)+3, \\
3 x(0)+2 x(1)=1, \quad x^{\prime}(0)+3 x^{\prime}(1)=2.5 . \\
\text { Here } \alpha=3 / 2, \gamma=1 / 2, T=1, m=1, a_{1}=3, b_{1}=2, \\
c_{1}=1, a_{2}=1, b_{2}=3, \text { and } c_{2}=2.5 . \text { In the context of this } \\
\text { problem, we have } \\
|f(t, x)|=\left|5 t^{2}+e^{-|x|}+\sin x\right| \leq 7, \quad t \in[0,1], x \in \mathbb{R}, \\
\left|I_{k}(x)\right| \leq 2, \quad\left|I_{k}^{*}(x)\right| \leq 4, \quad x \in \mathbb{R} .
\end{gathered}
$$

Put $h(t) \equiv 7, H_{1}=2$, and $H_{2}=4$; we know that the condition (51) holds. Then from Theorem 13, the impulsive fractional $\operatorname{BVP}(64)$ has at least one solution on $[0,1]$.

\section{Conclusions}

In this paper, we investigated the existence and uniqueness of solutions for a class of fractional differential equations with fractional impulsive conditions and nonseparated boundary conditions. We obtained the results by using Schaefer fixed point theorem, Banach fixed point theorem, and nonlinear alternative of Leray-Schauder type. And two examples are provided in Section 4 to illustrate the results.

\section{Conflict of Interests}

The authors declare that there is no conflict of interests regarding the publication of this paper.

\section{Acknowledgments}

This work is supported by the Doctor Priming Fund Project of University of South China (Grant no. 2013XQD16).

\section{References}

[1] J. Sabatier, O. P. Agrawal, and J. A. T. Machado, Eds., Advances in Fractional Calculus: Theoretical Developments and Applications in Physics and Engineering, Springer, Dordrecht, The Netherlands, 2007.

[2] V. Lakshmikantham, S. Leela, and J. Vasundhara Devi, Theory of Fractional Dynamic Systems, Cambridge Scientific Publishers, 2009.
[3] R. Hilfer, Applications of Fractional Calculus in Physics, World Scientific, Singapore, 2000.

[4] A. A. Kilbas, H. M. Srivastava, and J. J. Trujillo, Theory and Applications of Fractional Differential Equations, vol. 204 of North-Holland Mathematics Studies, Elsevier Science, Amsterdam, The Netherlands, 2006.

[5] A. H. Bhrawy, M. M. Alghamdi, and T. M. Taha, "A new modified generalized Laguerre operational matrix of fractional integration for solving fractional differential equations on the half line," Advances in Difference Equations, vol. 2012, article 179, 2012.

[6] A. H. Bhrawy, D. Baleanu, and L. M. Assas, "Efficient generalized Laguerre-spectral methods for solving multi-term fractional differential equations on the half line," Journal of Vibration and Control, vol. 20, no. 7, pp. 973-985, 2014.

[7] A. Yakar, "Initial time difference quasilinearization for Caputo fractional differential equations," Advances in Difference Equations, vol. 2012, article 92, 9 pages, 2012.

[8] A. Yakar and M. E. Koksal, "Existence results for solutions of nonlinear fractional differential equations," Abstract and Applied Analysis, vol. 2012, Article ID 267108, 12 pages, 2012.

[9] A. Yakar, "Some generalizations of comparison results for fractional differential equations," Computers and Mathematics with Applications, vol. 62, no. 8, pp. 3215-3220, 2011.

[10] V. Lakshmikantham, D. D. Bainov, and P. S. Simeonov, Theory of Impulsive Differential Equations, World Scientific, Singapore, 1989.

[11] A. M. Samoilenko and N. A. Perestyuk, Impulsive Differential Equations, World Scientific, Singapore, 1995.

[12] S. T. Zavalishchin and A. N. Sesekin, Dynamic Impulse Systems: Theory and Applications, vol. 394, Kluwer Academic, Dodrecht, The Netherlands, 1997.

[13] Z. Luo and J. Shen, "Stability of impulsive functional differential equations via the Liapunov functional," Applied Mathematics Letters. An International Journal of Rapid Publication, vol. 22, no. 2, pp. 163-169, 2009.

[14] Z. He and J. Yu, "Periodic boundary value problem for firstorder impulsive ordinary differential equations," Journal of Mathematical Analysis and Applications, vol. 272, no. 1, pp. 6778, 2002.

[15] W. Wei, X. Xiang, and Y. Peng, "Nonlinear impulsive integrodifferential equations of mixed type and optimal controls," Optimization, vol. 55, no. 1-2, pp. 141-156, 2006.

[16] M. Benchohra, S. Hamani, and J. J. a. Nieto, "Existence of solutions to differential inclusions with fractional order and impulses," Electronic Journal of Differential Equations, no. 80, pp. 1-18, 2010.

[17] M. Benchohra and S. Hamani, "The method of upper and lower solutions and impulsive fractional differential inclusions," Nonlinear Analysis: Hybrid Systems, vol. 3, no. 4, pp. 433-440, 2009.

[18] X. Y. Liu and Y. L. Liu, "Fractional differential equations with fractional non-separated boundary conditions," Electronic Journal of Differential Equations, vol. 2013, 13 pages, 2013.

[19] B. Ahmad and S. Sivasundaram, "Existence of solutions for impulsive integral boundary value problems of fractional order," Nonlinear Analysis. Hybrid Systems, vol. 4, no. 1, pp. 134$141,2010$.

[20] G. Wang, B. Ahmad, and L. Zhang, "Impulsive anti-periodic boundary value problem for nonlinear differential equations of fractional order," Nonlinear Analysis: Theory, Methods \& Applications, vol. 74, no. 3, pp. 792-804, 2011. 
[21] T. L. Guo and J. Wei, "Impulsive problems for fractional differential equations with boundary value conditions," Computers \& Mathematics with Applications, vol. 64, no. 10, pp. 3281-3291, 2012.

[22] N. Kosmatov, "Initial value problems of fractional order with fractional impulsive conditions," Results in Mathematics, vol. 63, no. 3-4, pp. 1289-1310, 2013.

[23] M. Fečkana, Y. Zhou, and J. Wang, "On the concept and existence of solution for impulsive fractional differential equations," Communications in Nonlinear Science and Numerical Simulation, vol. 17, no. 7, pp. 3050-3060, 2012.

[24] J. Wang, Y. Zhou, and M. Feckan, "On recent developments in the theory of boundary value problems for impulsive fractional differential equations," Computers \& Mathematics with Applications, vol. 64, no. 10, pp. 3008-3020, 2012.

[25] B. Ahmad and S. K. Ntouyas, "Some existence results for boundary value problems of fractional differential inclusions with non-separated boundary conditions," Electronic Journal of Qualitative Theory of Differential Equations, vol. 71, pp. 1-17, 2010.

[26] B. Ahmad, J. J. Nieto, and A. Alsaedi, "Existence and uniqueness of solutions for nonlinear fractional differential equations with non-separated type integral boundary conditions," Acta Mathematica Scientia, vol. 31, no. 6, pp. 2122-2130, 2011.

[27] A. Cernea, "Some remarks on a fractional differential inclusion with non-separated boundary conditions," Electronic Journal of Qualitative Theory of Differential Equations, vol. 45, pp. 1-14, 2011.

[28] A. Granas and J. Dugundji, Fixed Point Theory, Springer, New York, NY, USA, 2003.

[29] D. R. Smart, Fixed Point Theorems, Cambridge University Press, London, UK, 1974. 


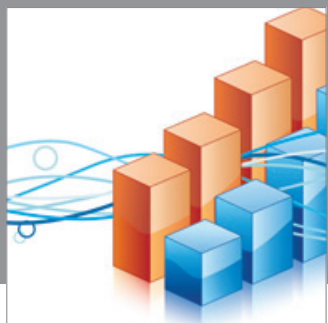

Advances in

Operations Research

mansans

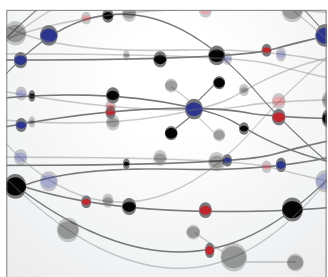

The Scientific World Journal
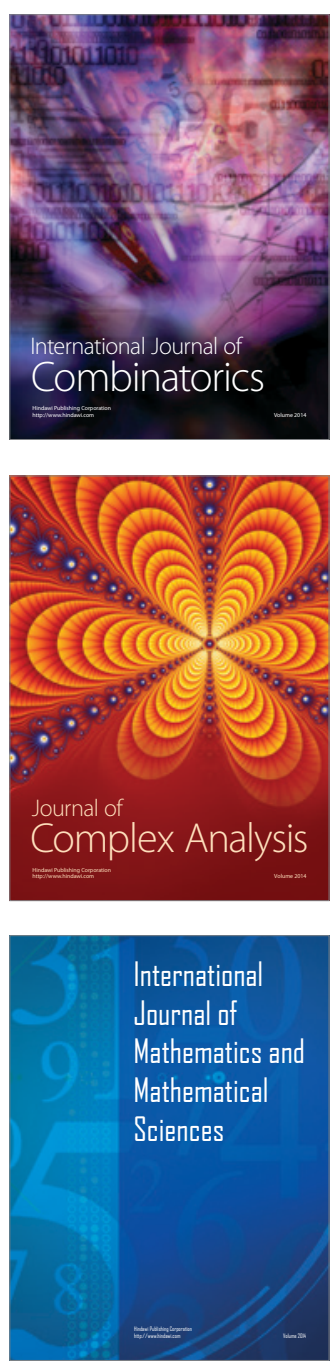
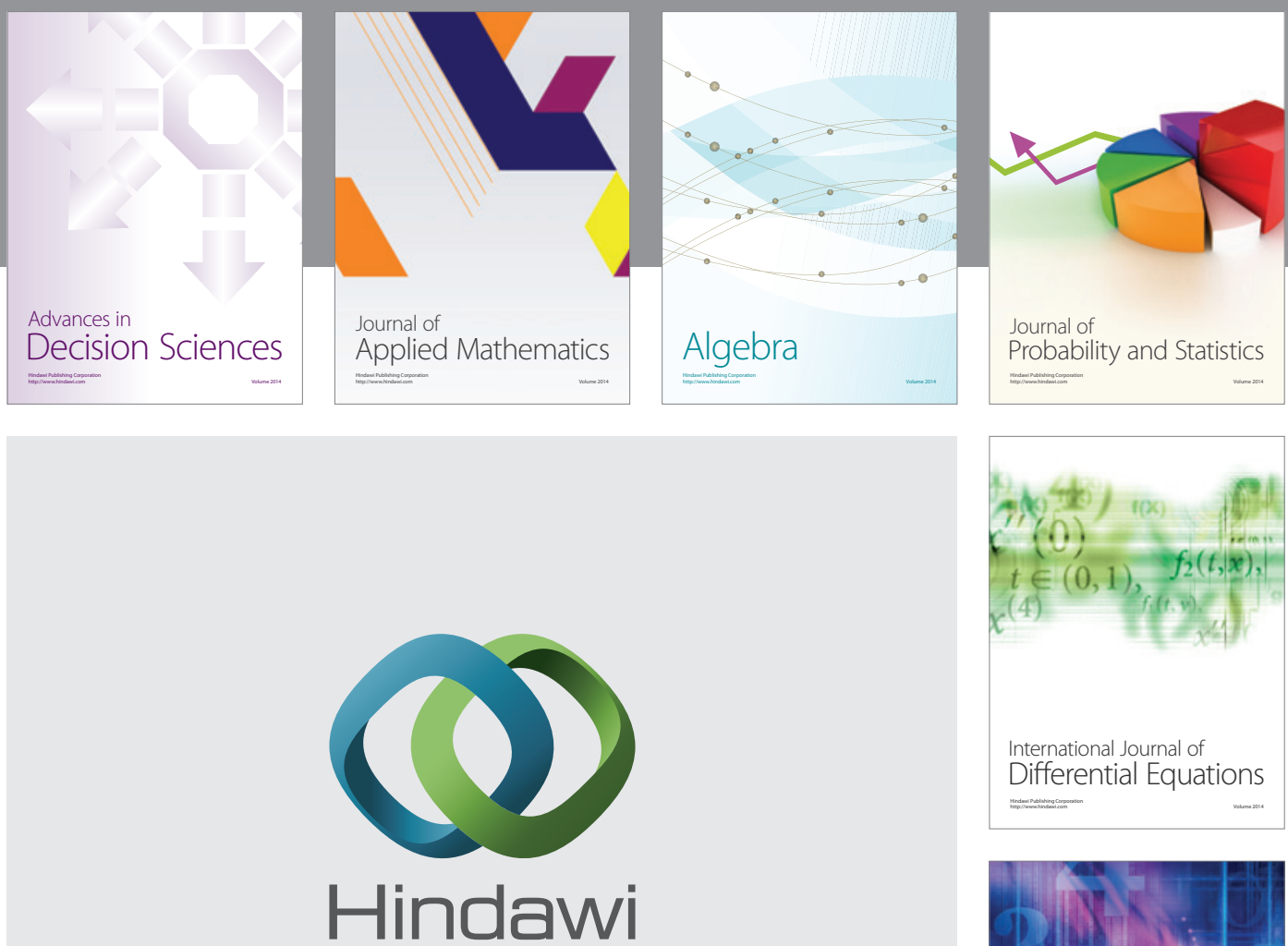

Submit your manuscripts at http://www.hindawi.com
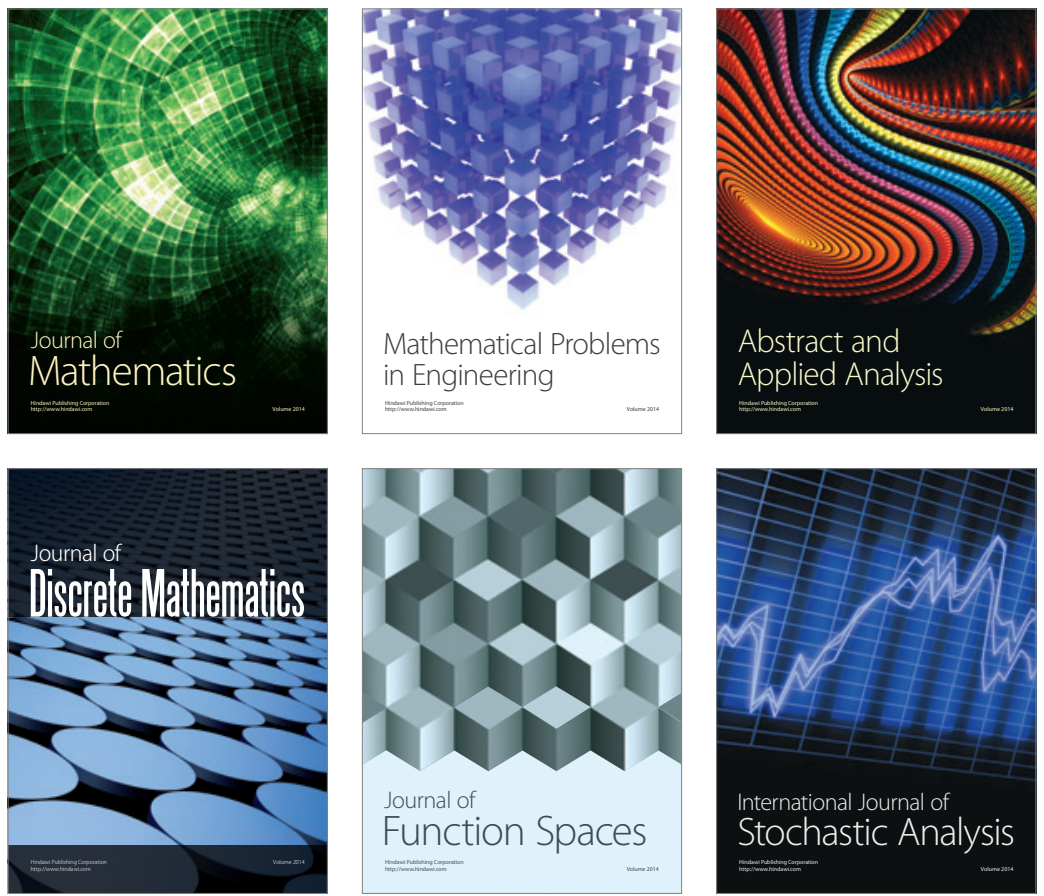

Journal of

Function Spaces

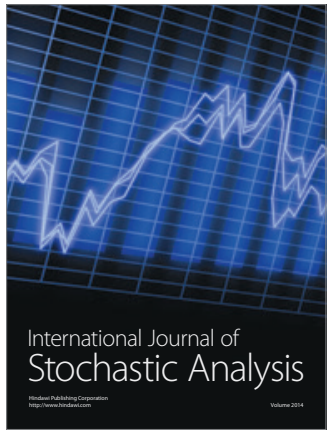

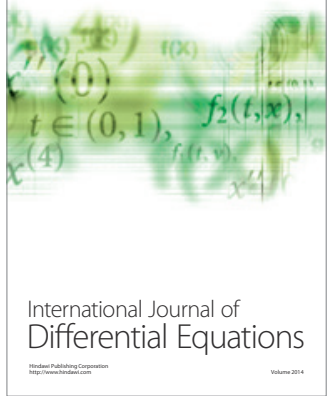
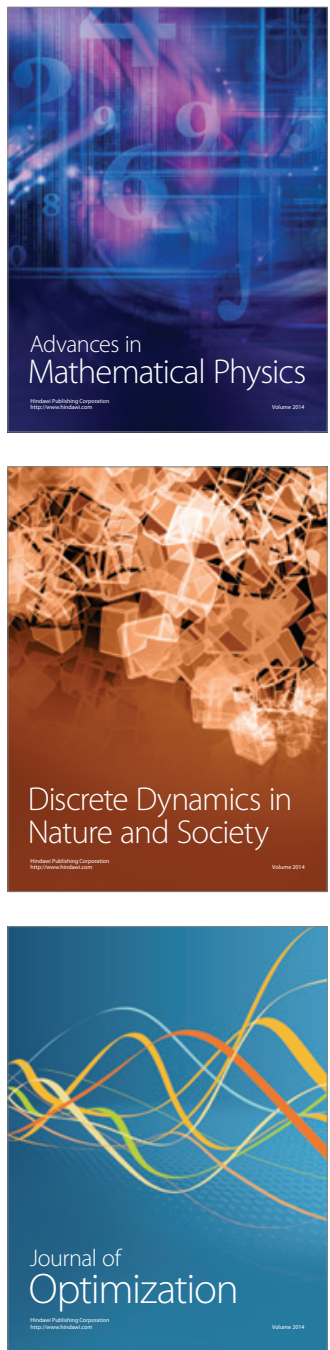